\title{
Treating pediatric atopic dermatitis: current perspectives
}

This article was published in the following Dove Press journal:

Pediatric Health, Medicine and Therapeutics

25 June 2015

Number of times this article has been viewed

\section{Victoria R Dimitriades Elizabeth Wisner \\ Division of Allergy/lmmunology, Department of Pediatrics, Louisiana State University Health Sciences Center, Children's Hospital of New Orleans, New Orleans, LA, USA}

\begin{abstract}
Atopic dermatitis (AD) is a chronic, inflammatory skin condition which affects millions of people worldwide. It is most commonly seen in children but may also progress into adulthood. Management of this complex disease requires a multi-pronged approach which can address the myriad of issues which underscore its development. Avoidance of triggering factors is imperative in establishing consistent control of skin irritation while daily moisturization can be very effective in skin barrier repair and maintenance. Judicious use of anti-inflammatory medications has been shown to make a significant impact on both treatment as well as prevention of disease. Unfortunately, pruritus, a key feature of $\mathrm{AD}$, has proven much harder to control. Finally, awareness of the risks of colonization and infection in patients with AD should be incorporated into their surveillance and management plans. While our understanding has progressed greatly regarding this disease, further research is still needed regarding future directions for both treatment and prevention.
\end{abstract}

Keywords: atopic dermatitis, eczema, treatment, corticosteroids, antipruritic

\section{Introduction}

Atopic Dermatitis (AD) was first officially described in 1933, though reports of its identification may have begun as early as $1796 .{ }^{1}$ This chronic, pruritic, inflammatory skin condition is most commonly seen in children (up to $25 \%$ lifetime prevalence), but $2 \%-3 \%$ may also continue into adulthood. ${ }^{2}$ The general pediatrician is the most frequent physician who manages this disease, but more refractory cases are also managed by dermatologists and allergists. For this review, we will outline general management strategies for the treatment of $\mathrm{AD}$ as well as address recent recommendations for prevention as well.

Patients with AD report that it has a higher impact on their quality of life when compared to patients with other atopic diseases. The goal of therapy for AD, therefore, should focus on improving quality of life by keeping skin healthy repairing barrier function, minimizing pruritus, and preventing flare of disease. In order to do this, our practice has focused on a five-step plan which not only allows for a multifaceted approach to treating disease, but which also engages the patient and their family in their own medical care. By using visual cues for this treatment plan (Figure 1), we are able to clarify the components of therapy which are most effective in controlling AD symptoms. The five "A's" of AD care include: avoidance of triggers, application of cleanser and moisturizer, anti-inflammatory, anti-itch, and anti-bacteria.
Correspondence: Victoria R Dimitriades Division of Allergy/lmmunology, Department of Pediatrics, Louisiana State University Health Sciences Center, Children's Hospital of New Orleans, 200 Henry Clay Avenue, New Orleans, LA 70I I8, USA

Tel +I 5048969589

Fax + I 50489693 II

Email varsen@Isuhsc.edu 


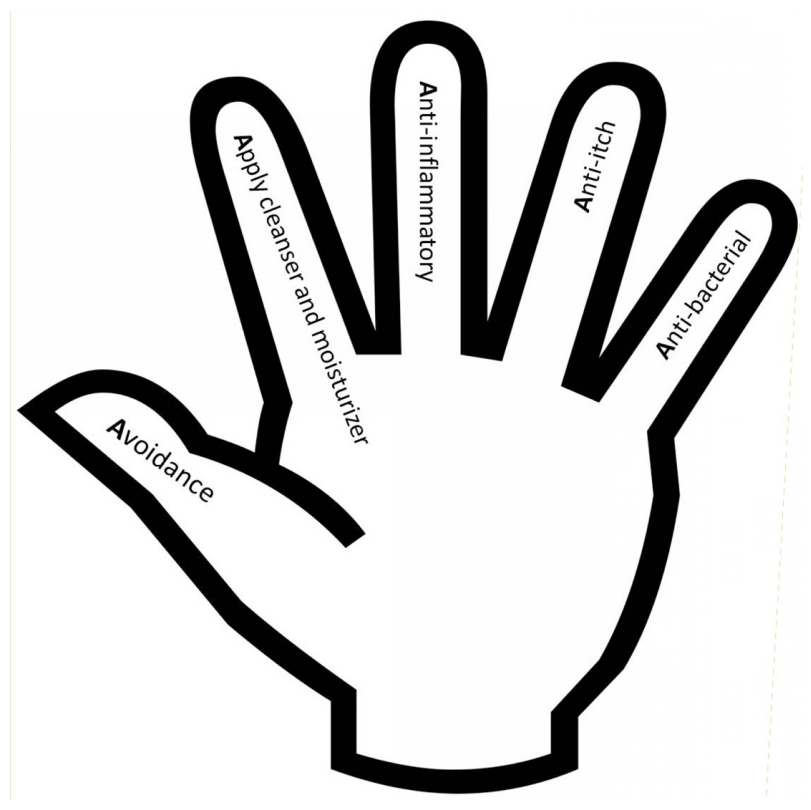

Figure I The five "A's" of atopic dermatitis care.

\section{Avoidance}

In order to minimize the ongoing stimulus for the underlying inflammation of $A D$, patients are advised to avoid triggers such as specific foods, seasonal or perennial allergens, and irritants. Because each patient may not display flares in response to any or all of these triggers, the list should be tailored to the individual patient. Food and allergens which worsen dermatitis may be found in a significant portion of patients who are recalcitrant to initial therapies. In these cases, avoidance of these allergens will improve overall skin control. However, many patients, regardless of allergen sensitization, are still reactive to environmental irritants: excessive bathing, emotional stress, exposure to solvents and detergents, overheating of the skin, and low humidity environments. ${ }^{3}$

Although there is no recommended diet specific for AD, food allergy testing and/or specific food avoidance should be considered in cases refractory to treatment. Up to $30 \%$ of infants and young children and $10 \%$ of older children with moderate to severe AD have food-induced flares. ${ }^{4}$ Among food allergens, cow's milk, hen's egg, wheat, soy, tree nuts, and peanuts are most frequently responsible for AD flares in infancy. ${ }^{5}$ Identification of potential IgE-related food sensitizations can be done by either skin prick testing or serum specific-IgE testing. Both false-positive and false-negative IgE-mediated tests can occur, so testing is a supportive rather than a diagnostic measure. It is more commonly recommended that the clinical history should guide the exclusion of specific foods: when an identified food is in question, the patient can exclude that food for a trial period of 4 weeks to assess for improvement in $\mathrm{AD} .{ }^{4}$ In practice, results often are present within 2 weeks and patients with a clear history of eczema flares after eating specific foods are most likely to benefit from avoidance trials. A Cochrane review of nine randomized controlled trials of food exclusion concluded that there is no benefit of empiric milk and egg exclusion, severely restricted food diets, or elemental diets in unselected patients with AD. ${ }^{6}$ However, in very young patients refractory to standard treatment with moisturization and topical anti-inflammatories, a trial off of cow's milk may be useful. Additionally, food-related flares may be outgrown, so re-evaluation is recommended in 6- to 12-month intervals. ${ }^{4}$ If dietary avoidance of specific foods is instituted, especially of dairy products, consultation with a dietician is recommended to prevent nutritional deficiencies.

Sensitization to aeroallergens is not uncommon in patients with AD. Such allergens can exacerbate AD via inhalation, direct contact with the skin, or ingestion. Of the known inhalants, dust mites and animal dander have been shown to be the most common culprits, as identified by patch testing, avoidance studies, and high titers of IgE antibodies to mite proteins. ${ }^{7}$ The most common airborne allergens eliciting AD are derived from house dust mites of the species Dermatophagoides pteronyssinus and Dermatophagoides farinae. ${ }^{5}$ They are most commonly present in mattresses or carpeted floors, and encasing pillows and mattresses can help to decrease the exposure of vulnerable individuals. Cat epithelia exposure should be avoided in patients with $\mathrm{AD}$, although there is currently no recommendation regarding exposure to dogs. ${ }^{5}$ Patients with AD have been shown to have lower contact irritant thresholds, likely due to skin barrier dysfunction caused by loss of hydration. ${ }^{8}$ For this reason, they are counseled to avoid chemical and fragrance irritants including harsh soaps and detergents. Additionally, in the setting of stress, sensory nerves of the skin release neuromediators that regulate inflammatory and immune responses as well as barrier function. ${ }^{9}$ For patients with AD, psychological stress can lead to increase in itching and skin barrier breakdown; behavioral therapy and stress management counseling have been helpful in this regard. ${ }^{9}$

\section{Application of cleanser and moisturizer}

The subject of skin cleansing is a much-debated topic for patients with AD. There is no agreed-upon method for this (bath versus shower), though the skin should be cleansed thoroughly but gently. Harsh soaps and hot water temperature during bathing or showering can further irritate already inflamed 
skin, though non-soap-based surfactants, synthetic detergents with an acidic or neutral $\mathrm{pH}$, and lipid-free cleansing lotions may be used. Neither water alone nor as tringents are recommended for cleansing. ${ }^{10}$ We recommend that tepid water should be used for bathing or showering and the duration of the cleansing ritual should be limited to 20 minutes or less. Patting of the skin as opposed to rubbing is also preferred, as to not induce further trauma.

Effective moisturization is quite possibly the most important component of treatment, as you will rarely see a patient with well-moisturized skin who is having a significant flare. Moisturization not only helps to improve skin barrier function, but also helps to reduce the skin's susceptibility to irritants and subsequent inflammation. If applied correctly, moisturization can reduce the dependency on topical corticosteroids. ${ }^{11}$ We recommend that moisturization should take place at least twice daily and immediately after bathing and hand washing. In general, the thicker moisturizers (creams, rather than lotions or milks) have less alcohol and/ or water content and allow for better hydration of the skin. Emollients, which are the basis of many moisturizers, have essential fatty acids and natural oils help to improve the appearance and texture of the skin by filling in the crevices between corneocytes. They may also contain occlusive substances, like petrolatum, which work by forming a hydrophobic layer on the skin's surface, thus creating a barrier to water loss. Humectants (like glycerol or glycerin) are also often added to emollients to enhance water absorption from the dermis into the epidermis. Finally, ceramides, which are an essential component of the normal stratum corneum, are used to help maintain the integrity of the skin barrier. ${ }^{12}$ Moisturizers may be made up of any combinations of these products; each patient should find a product which they find acceptable and use at the frequency recommended. It must be noted that studies reviewing use of daily emollients have shown benefits of daily use, regardless of the make-up of the moisturization product. ${ }^{11}$

\section{Anti-inflammatory Corticosteroids}

Topical steroids are the cornerstone of pharmacologic therapy for $\mathrm{AD}$ as they can treat both the acute and chronic inflammation associated with disease. Steroids decrease production of proinflammatory cytokines and can help control both local irritation as well as pruritus. ${ }^{13}$ Adequate corticosteroid treatment, however, involves the correct application of a product with both sufficient strength and dosage. Corticosteroids are classified in the United States into seven categories, ranging from Class I (highest potency) to Class VII (lowest potency). In general, use of the lowest potency of a steroid is preferable for frequent application, though use of higher potencies may be necessary when treating more severe or refractory disease. It is also important to note that the vehicle in which the corticosteroid product is formulated (ointment versus cream) will alter its potency. Table 1 is a summary of commonly prescribed corticosteroids separated by relative potency with a reference to amounts which can be dispensed. One must also be mindful of the surface area which will need to be covered during treatment in order to prescribe an adequate amount. For example, one hand-sized area of the body would use about $0.25 \mathrm{~g}$ of steroids while a full-body application for an adult would use about $20 \mathrm{~g} \cdot{ }^{14}$

We instruct our patients to use topical steroids in the areas of dermatitis twice per day during periods of flare. For a patient who needs treatment infrequently, a low-potency steroid should suffice. In patients with chronic disease, however, use of medium- or even high-potency steroids may be warranted for short periods. Patients are instructed to use coin-sized amounts of steroids on clean fingertips to apply a thin layer to the most affected areas and to spread it out from there. For patients using emollients which are cream-based, we recommend moisturization first, and then application of the steroid to trouble spots several minutes later. If they are using an ointment-based form of hydration, we recommend application of the steroid first so that the occlusive barrier does not prevent the steroid from being absorbed.

For patients with acute flares who do not respond to first-line topical therapy, use of short-term daily wet-wrap therapy has been found to be effective means to control inflammation without need for further immunosuppression. ${ }^{15}$ The patient is soaked in a tepid bath for 15-20 minutes, patted dry, and topical corticosteroid is applied to inflamed areas. These areas are then wrapped in a layer of warm, moistened gauze followed by a layer of dry gauze. This application can be left on for 2-4 hours and then removed.

Once flare is resolved, proactive maintenance therapy with twice weekly applications of low-potency topical corticosteroids to previously affected areas of skin has been shown to reduce exacerbations of AD. ${ }^{16}$ This approach can result in reduced overall necessity of topical corticosteroids as well.

Side effects of corticosteroids are infrequent when applied in low doses and intermittently over a long period of time. High-dose and long-term daily use, however, can cause susceptibility to atrophy, hypopigmentation, secondary infection, acne, and striae. ${ }^{4}$ Avoidance of corticosteroids on the areas of thin skin found on the face, axilla, and groin is recommended 
Table I Topical steroids identified by potency and availability

\begin{tabular}{|c|c|c|c|}
\hline Potency & Medication & Vehicle & Size available \\
\hline \multirow[t]{4}{*}{ Class I (Ultra high) } & Betamethasone dipropionate $0.05 \%$ & O & $15 \mathrm{~g}, 45 \mathrm{~g}$ \\
\hline & Clobetasol propionate $0.05 \%$ & $\mathrm{O}, \mathrm{C}$ & $15-60 \mathrm{~g}$ \\
\hline & & L & $30-120 \mathrm{~mL}$ \\
\hline & Halobetasol propionate $0.05 \%$ & $\mathrm{O}, \mathrm{C}$ & $15 \mathrm{~g}, 50 \mathrm{~g}$ \\
\hline \multirow[t]{5}{*}{ Class II (High) } & Betamethasone dipropionate $0.05 \%$ & C & $15 \mathrm{~g}, 45 \mathrm{~g}$ \\
\hline & Desoximetasone $0.25 \%$ & $\mathrm{O}, \mathrm{C}$ & $15 \mathrm{~g}, 60 \mathrm{~g}, 100 \mathrm{~g}$ \\
\hline & Fluocinonide $0.05 \%$ & $\mathrm{O}, \mathrm{C}$ & $30 \mathrm{~g}, 60 \mathrm{~g}$ \\
\hline & Halcinonide $0.1 \%$ & $\mathrm{O}, \mathrm{C}$ & $15 \mathrm{~g}, 30 \mathrm{~g}, 60 \mathrm{~g}$ \\
\hline & Mometasone furoate $0.1 \%$ & $\mathrm{O}$ & $15 \mathrm{~g}, 45 \mathrm{~g}$ \\
\hline \multirow[t]{4}{*}{ Class III (Medium to high) } & Betamethasone dipropionate $0.05 \%$ & L & $30 \mathrm{~mL}, 60 \mathrm{~mL}$ \\
\hline & Desoximetasone $0.05 \%$ & C & $15 \mathrm{~g}, 60 \mathrm{~g}$ \\
\hline & Fluticasone propionate $0.005 \%$ & O & $15 \mathrm{~g}, 30 \mathrm{~g}$ \\
\hline & Triamcinolone acetonide $0.5 \%$ & $\mathrm{O}, \mathrm{C}$ & $15 \mathrm{~g}$ \\
\hline \multirow[t]{7}{*}{ Class IV (Medium) } & Fluocinolone acetonide $0.025 \%$ & O & $15 \mathrm{~g}, 30 \mathrm{~g}, 60 \mathrm{~g}$ \\
\hline & Hydrocortisone butyrate $0.1 \%$ & O & $15 \mathrm{~g}, 45 \mathrm{~g}$ \\
\hline & Hydrocortisone valerate $0.2 \%$ & O & $15 \mathrm{~g}, 45 \mathrm{~g}, 60 \mathrm{~g}$ \\
\hline & Mometasone furoate $0.1 \%$ & O & $15 \mathrm{~g}, 45 \mathrm{~g}$ \\
\hline & Triamcinolone acetonide $0.1 \%$ & O & $15-454 \mathrm{~g}$ \\
\hline & & C & $15 \mathrm{~g}, 60 \mathrm{~g}, 80 \mathrm{~g}$ \\
\hline & & $\mathrm{L}$ & $60 \mathrm{~mL}$ \\
\hline \multirow[t]{9}{*}{ Class V (Medium to low) } & Betamethasone valerate $0.1 \%$ & C & $15 \mathrm{~g}, 45 \mathrm{~g}$ \\
\hline & Fluocinolone acetonide $0.025 \%$ & C & $15 \mathrm{~g}, 30 \mathrm{~g}, 60 \mathrm{~g}$ \\
\hline & Hydrocortisone butyrate $0.1 \%$ & C & $15 \mathrm{~g}, 45 \mathrm{~g}, 60 \mathrm{~g}$ \\
\hline & Hydrocortisone valerate $0.2 \%$ & C & $15 \mathrm{~g}, 45 \mathrm{~g}, 60 \mathrm{~g}$ \\
\hline & Mometasone furoate $0.1 \%$ & C & $15 \mathrm{~g}, 45 \mathrm{~g}$ \\
\hline & & $\mathrm{L}$ & $30 \mathrm{~mL}, 60 \mathrm{~mL}$ \\
\hline & Triamcinolone acetonide $0.025 \%$ & O & $15-454 \mathrm{~g}$ \\
\hline & & C & $15 \mathrm{~g}, 80 \mathrm{~g}$ \\
\hline & & L & $60 \mathrm{~mL}$ \\
\hline \multirow[t]{4}{*}{ Class VI (Low) } & Alclometasone dipropionate $0.05 \%$ & $\mathrm{O}, \mathrm{C}$ & $15 \mathrm{~g}, 45 \mathrm{~g}, 60 \mathrm{~g}$ \\
\hline & Desonide $0.05 \%$ & C & $15 \mathrm{~g}, 60 \mathrm{~g}$ \\
\hline & & $\mathrm{L}$ & $60 \mathrm{~mL}, 120 \mathrm{~mL}$ \\
\hline & Fluocinolone acetonide $0.01 \%$ & C & $15 \mathrm{~g}, 60 \mathrm{~g}$ \\
\hline \multirow[t]{2}{*}{ Class VII (Mild) } & Hydrocortisone $0.5 \%-2.5 \%$ & $\mathrm{O}, \mathrm{C}$ & $15-454 \mathrm{~g}$ \\
\hline & & L & $60 \mathrm{~mL}, 120 \mathrm{~mL}$ \\
\hline
\end{tabular}

Abbreviations: $\mathrm{O}$, ointment; $\mathrm{C}$, cream; L, lotion.

when possible (though short-term low-potency treatment is acceptable).

Oral corticosteroids are reserved for only the most severe cases; they may be used in short courses for patients who have not responded to treatment, despite optimal medical management. Longer courses of oral steroids, in our experience, confer risk for recurrence of flare after cessation of treatment.

\section{Calcineurin inhibitors}

Topical calcineurin inhibitors suppress local $\mathrm{T}$ cell responses and inflammation. However, unlike topical corticosteroids, topical calcineurin inhibitors do not have an effect on Langerhans' cells and do not reduce the number of helper T cells in healthy skin. ${ }^{17}$ They have not been associated with systemic immunosuppression, atrophy or hypopigmentation and have become more widely used as steroid-sparing agents for control of inflammation in AD. They are safe to use in the thinner skin of the face, groin, and axillae and have recently been shown to have a superior effect on skin barrier repair compared to corticosteroids. ${ }^{18}$ Earlier safety concerns regarding a theoretical risk of lymphoma with use of these products (even in patients less than 2 years of age) have largely been refuted as a comprehensive body of evidence from clinical studies, post-marketing surveillance, and epidemiological investigations has not supported previous safety concerns. ${ }^{19}$

Topical pimecrolimus and tacrolimus are available in different strengths and both ointment and cream preparations, though some patients report minor skin irritation with use of the ointment preparation. They may be used in the same frequency as topical steroids, both during flare as well as in a prophylactic management plan. 


\section{UV light therapy}

Phototherapy can impact AD in that it has been found to induce apoptosis of inflammatory cells, reduce Staphylococcus aureus colonization, and decrease the thickness of the stratum corneum..$^{20}$ UVA1 and narrow-band UVB therapies have been advocated in some patients with recalcitrant $\mathrm{AD}$, though this should be done with the aid of a specialist.

\section{Immunosuppression}

Other forms of therapy, including the systemic calcineurin inhibitor cyclosporine, have been reserved in the cases of severe refractory AD. Recent literature has shown that cyclosporine controls dermatitis by significantly suppressing inflammatory $\mathrm{T}$ cell subsets related to the $\mathrm{AD}$ phenotype within lesional skin. ${ }^{21}$ However, because of the risk of renal toxicity, patients need to be monitored closely for secondary effects. Antimetabolites such as methotrexate, mycophenolate mofetil, and azathioprine have also been used to control severe $\mathrm{AD}$, though these should be selected by individual risk assessment for each patient.

\section{Anti-itch}

Pruritus is a difficult to control symptom in patients with AD. Treatment is multifactorial, involving the targeting of both xerosis and inflammation. Patients with AD and dry skin have increased epidermal nerve density and pruritus symptoms compared to healthy skin; use of emollients alone can normalize the nerve density and help control itching. ${ }^{22}$ Although oral antihistamines are commonly prescribed for patients with $\mathrm{AD}$, a review of 16 controlled studies found little evidence for their effectiveness in pruritus. ${ }^{23}$ However, there may be some benefit for patients using antihistamines to also control concomitant urticaria or allergic rhinitis. ${ }^{24}$ When prescribed, the sedating first generation antihistamines appear to be the most effective, likely due to decreased scratching while sleeping, while non-sedating antihistamines seem to only have modest value. ${ }^{7}$ One must use caution, however, in prescribing sedating antihistamines, especially to small infants, who are more predisposed to overdose. Overall, topical therapies are more effective, as reviewed by a recent meta-analysis of 52 randomized controlled trials: both topical glucocorticoids and calcineurin inhibitors showed a rapid antipruritic effect and are effective to help to break the itch-scratch cycle when applied soon after onset of pruritus..$^{25}$ In patients who can tolerate it, topical treatments with camphor, menthol, or urea may also be helpful as well. ${ }^{26}$

\section{Anti-bacterial}

S. aureus colonization is present in up to $90 \%$ of patients with moderate to severe eczema and is felt to be related to pathogenesis of ongoing inflammation. ${ }^{27}$ Regardless of the high rates of colonization, anti-staphylococcal treatments have not been helpful in uninfected eczema. ${ }^{28}$ When true infection is present, however, an appropriate anti-staphylococcus antibiotic should be chosen based on community sensitivities and resistance patterns. In areas where there is a high rate of methicillin-resistant $S$. aureus (MRSA), it may be beneficial to take a swab culture to guide therapy selection. ${ }^{24}$ In our population of patients, we find that use of the anti-staphylococcal antibiotic cephalexin is often not very effective and will use clindamycin or trimethoprim-sulfamethoxazole instead, as these have better MRSA coverage. If an infection does not respond in 1-2 days of empiric antibiotics, a culture with antibiotic sensitivity screening should be taken in order to ensure proper antibacterial coverage. In addition to oral antibiotic therapy, diluted bleach (sodium hypochlorite) baths may reduce the need for systemic antibiotics and have been shown to decrease disease severity. Current recommendations include adding one quarter to one half cup of bleach per 40-gallon bath. Soaking twice weekly may result in dramatic improvement in some patients. ${ }^{29}$ After soaking, patients should also be instructed to rinse with non-treated water and moisturize well following their bath so that the bleach does not cause further drying of their skin.

In addition to staphylococcus infections, other microbes can cause flares and should be considered in a patient who is not improving despite optimal medical management. Fungal superinfection with Malassezia species can be seen, predominantly presenting with flaky, dry patches in the head and neck area. This more often responds to long-term systemic, rather than topical, therapy ${ }^{30}$ Furthermore, ongoing dermatitis with the development of clustered vesicles or shallow ulcers on an erythematous base should suggest the development of a secondary infection with the herpes simplex virus. Eczema herpeticum is a serious dermatologic condition requiring prompt recognition and treatment with systemic antiviral therapy. Finally, because of compromised barriers and use of corticosteroids, patients with $\mathrm{AD}$ are also susceptible to Molluscum contagiosum. These virally-induced lesions appear as pale, clustered papules with a central area of umbilication. Generally, treatment is supportive, but with ongoing scratching causing self-inoculation, this may become a more widespread issue which requires topical antiviral therapy or cryotherapy. 


\section{Adjuvant therapies}

Although not currently part of a primary regimen for $\mathrm{AD}$ control, there are other therapies which have been used to secondarily impact the severity of AD.

\section{Vitamin D}

Several observational studies have demonstrated the association between low vitamin D levels and the prevalence and severity of AD. A recent review of the literature revealed several clinical trials in the last 10 years showing improvement of low vitamin D levels and AD severity scores with daily supplementation of 1,000-1,600 U of vitamin $\mathrm{D}$ or by using phototherapy. ${ }^{31}$

\section{Probiotics}

Early research on probiotics was found to be inconsistently beneficial because of variations of strains of probiotics studied, age of the patients, cultural/diet norms, and study design. Recent studies using Lactobacillus rhamnosus GG (LGG), Bifidobacterium lactis Bb-12, or a Lactobacillus fermentum/paracasei combination daily supplement have shown an improvement in $\mathrm{AD}$ severity scores and quality of life scores after using probiotics daily for 1-4 months; improvement was more pronounced in the patients who were less than 12 years of age. ${ }^{32}$

\section{Immunotherapy}

Allergen immunotherapy, both subcutaneous and sublingual, has been evaluated in patients with AD. Many randomized controlled studies have reported symptom improvement in patients; however, based on low power, inconsistent scoring systems, skewed patient selection, and differing study designs, these have been found to be low to moderate quality evidence at best. ${ }^{33}$

\section{Prevention}

In congruence with the finding that patients with good barrier preservation are less likely to have a flare or infection, two recent randomized trials have shown that promotion of an intact skin barrier by using daily emollients in the first month of life was associated with reduction in the incidence of AD in high-risk infants..$^{34,35}$ This will need to be further investigated in more long-term studies, but provides an easy and safe intervention early in life.

Probiotic trials were evaluated in a meta-analysis for preventive use and found to be helpful for reducing the risk of development of $\mathrm{AD}$ in both high-risk neonates as well as the general population. The majority of these trials used LGG probiotic species prenatally or postnatally, but confounding factors of antibiotic use and allergen avoidance were not necessarily consistent over the studies. ${ }^{36}$

Finally, the German Infant Nutritional Intervention found that, in patients with an atopic heredity who received supplemental formula in addition to breastfeeding, there was an allergy-preventive effect of hydrolyzed infant formulas on allergies and atopic eczema until 6 years of age (especially extensively hydrolyzed whey). ${ }^{37,38}$ Additional prospective trials will need to be performed in order to evaluate effects beyond this age as well.

\section{Partnership in patient care}

In the last 200 years of AD awareness, much has been learned regarding diagnosis, risk factors, treatment, and prevention of disease. We continue to use accumulated research in order to implement comprehensive management plans for our patients. In this endeavor, one of the most important aspects is to educate $\mathrm{AD}$ patients and their families regarding the pathology of the disease and the expected effect of therapy plans which are instituted. Without a patient-physician partnership, even the most effective treatments are likely to be ineffective. Easy-to-use written materials with simple action plans may be the most effective way to help your patients understand and control their disease.

\section{Disclosure}

The authors declare there are no conflicts of interest in relation to this work.

\section{References}

1. Wallach D, Coste J, Tilles G, Ta1eb A. The first images of atopic dermatitis: An attempt at retrospective diagnosis in dermatology. $J$ Am Acad Dermatol. 2005;53(4):684-689.

2. Eichenfield LF, Tom WL, Chamlin SL, et al. Guidelines of care for the management of atopic dermatitis Section 1. Diagnosis and assessment of atopic dermatitis. J Am Acad Dermatol. 2014;70(2):338-351.

3. Langan SM, Bourke JF, Silcocks P, Williams HC. An exploratory prospective observational study of environmental factors exacerbating atopic eczema in children. Br J Dermatol 2006;154(5):979-980.

4. Arkwright PD, Motala C, Subramanian H, et al. Management of Difficult-to-Treat Atopic Dermatitis. J Allergy Clin Immunol Pract. 2013;1(2):142-151.

5. Ring J, Alomar A, Bieber T, et al. Guidelines for treatment of atopic eczema (atopic dermatitis) part I. J Eur Ac Derm Venereol. 2012;26(8): 1045-1060.

6. Bath-Hextall F, Delamere FM, Williams HC. Dietary exclusions for established atopic eczema. Cochrane Database Syst Rev. 2008;(1): CD005203.

7. Akdis CA, Akdis M, Bieber T, et al. Diagnosis and treatment of atopic dermatitis in children and adults: PRACTALL Consensus Report. Allergy. 2006;61(8):969-987.

8. Darlenski R, Kazandjieva J, Tsankov N, Fluhr JW. Acute irritant threshold correlates with barrier function, skin hydration and contact hypersensitivity in atopic dermatitis and rosacea. Exp Dermatol. 2013;22(11):752-753. 
9. Suarez AL, Feramisco JD, Koo J, Steinhoff M. Psychoneuroimmunology of Psychological Stress and Atopic Dermatitis: Pathophysiologic and Therapeutic Updates. Acta Derm Venereol. 2012;92(1):7-15.

10. Cheong WK. Gentle cleansing and moisturizing for patients with atopic dermatitis and sensitive skin. Am J Clin Dermatol. 2009;10 Suppl 1: 13-17.

11. Ng JP, Liew HM, Ang SB. Use of emollients in atopic dermatitis. J Eur Acad Dermatol Venereol. 2015;29(5):854-857.

12. Nolan K, Marmur E. Moisturizers: Reality and the skin benefits. Dermatol Ther. 2012;25(3):229-233.

13. Eichenfield LF, Tom WL, Berger T, et al. Guidelines of care for the management of atopic dermatitis Section 2. Management and treatment of atopic dermatitis with topical therapies. J Am Acad Dermatol. 2014;71(1):116-132.

14. Ference JD, Last AR. Choosing Topical Steroids. Am Fam Physician. 2009;79(2):135-140.

15. Nicol NH, Boguniewicz M, Strand M, Klinnert M. Wet wrap therapy in children with moderate to severe atopic dermatitis in a multidisciplinary treatment program. J Allergy Clin Immunol Pract. 2014;2(4): 400-406.

16. Schmitt J, von Kobyletzki L, Svensson A, Apfelbacher C. Efficacy and tolerability of proactive treatment with topical corticosteroids and calcineurin inhibitors for atopic eczema: systematic review and meta-analysis of randomized controlled trials. Br J Dermatol. 2011;164(2):415-428.

17. Carr WW. Topical calcineurin inhibitors for atopic dermatitis: review and treatment recommendations. Paediatr Drugs. 2013;15(4):303-310.

18. Aslam I, Sandoval LF, Feldman SR. What's new in the topical treatment of allergic skin diseases. Curr Opin Allergy Clin Immunol. 2014;14(5):436-450.

19. Luger T, Boguniewicz M, Carr W, et al. Pimecrolimus in atopic dermatitis: consensus on safety and the need to allow use in infants. Pediatr Allergy Immunol. Epub January 3, 2015.

20. Garritsen FM, Brouwer MW, Limpens J, Spuls PI. Photo(chemo) therapy in the management of atopic dermatitis: an updated systematic review with implications for practice and research. $\mathrm{Br} \mathrm{J}$ Dermatol. 2014;170(3):501-513.

21. Khattri S, Shemer A, Rozenblit M, et al. Cyclosporine in patients with atopic dermatitis modulates activated inflammatory pathways and reverses epidermal pathology. J Allergy Clin Immunol. 2014;133(6): $1626-1634$.

22. Tominaga M, Takamoria K. An Update on Peripheral Mechanisms and Treatments of Itch. Biol Pharm Bull. 2013;36(8):1241-1247.

23. Klein PA, Clark RA. An evidence-based review of the efficacy of antihistamines in relieving pruritus in atopic dermatitis. Arch Dermatol. 1999;135(12):1522-1525.
24. Lio PA, Lee M, LeBovidge J, Timmons KG, Schneider L. Clinical management of atopic dermatitis: practical highlights and updates from the atopic dermatitis practice parameter 2012. J Allergy Clin Immunol Pract. 2014;2(4):361-369.

25. Sher LG, Chang J, Patel IB, Balkrishnan R, Fleischer AB Jr. Relieving the Pruritus of Atopic Dermatitis: A Meta-analysis. Acta Derm Venereol. 2012;92(5):455-461.

26. Yarbrough KB, Neuhaus KJ, Simpson EL. The effects of treatment on itch in atopic dermatitis. Dermatol Ther. 2013;26(2):110-119.

27. Lee M, Van Bever $H$. The role of antiseptic agents in atopic dermatitis. Asia Pac Allergy. 2014;4(4):230-240.

28. Bath-Hextall FJ, Birnie AJ, Ravenscroft JC, Williams HC. Interventions to reduce Staphylococcus aureus in the management of atopic eczema: an updated Cochrane review. Br J Dermatol. 2010;163(1):12-26.

29. Wong SM, Ng TG, Baba R. Efficacy and safety of sodium hypochlorite (bleach) baths in patients with moderate to severe atopic dermatitis in Malaysia. J Dermatol. 2013;40(11):874-880.

30. Kaffenberger BH, Mathis J, Zirwas MJ. A retrospective descriptive study of oral azole antifungal agents in patients with patch test-negative head and neck predominant atopic dermatitis. J Am Acad Dermatol. 2014;71(3):480-483.

31. Mutgi K, Koo J. Update on the role of systemic vitamin D in atopic dermatitis. Pediatr Dermatol. 2013;30(3):303-307.

32. Wang IJ, Wang JY. Children with atopic dermatitis show clinical improvement after Lactobacillus exposure. Clin Exp Allergy. 2015; 45(4):779-787.

33. Gendelman SR, Lang DM. Specific immunotherapy in the treatment of atopic dermatitis: a systematic review using the GRADE system. Ann Allergy Asthma Immunol. 2013;111(6):555-561.

34. Simpson EL, Chalmers JR, Hanifin JM, et al. Emollient enhancement of the skin barrier from birth offers effective atopic dermatitis prevention. J Allergy Clin Immunol. 2014;134(4):818-823.

35. Horimukai K, Morita K, Narita M, et al. Application of moisturizer to neonates prevents development of atopic dermatitis. J Allergy Clin Immunol. 2014;134(4):824-830.

36. Panduru M, Panduru NM, Sălăvăstru CM, Tiplica GS. Probiotics and primary prevention of atopic dermatitis: a meta-analysis of randomized controlled studies. J Eur Acad Dermatol Venereol. 2015;29(2): 232-242.

37. von Berg A, Filipiak-Pittroff B, Krämer U, et al. Preventive effect of hydrolyzed infant formulas persists until age 6 years: long-term results from the German Infant Nutritional Intervention Study (GINI). J Allergy Clin Immunol. 2008;121(6):1442-1447.

38. Fleischer DM, Spergel JM, Assa'ad AH, Pongracic JA. Primary prevention of allergic disease through nutritional interventions. J Allergy Clin Immunol Pract. 2013;1(1):29-36.
Pediatric Health, Medicine and Therapeutics

\section{Publish your work in this journal}

Pediatric Health, Medicine and Therapeutics is an international, peerreviewed, open access journal publishing original research, reports, editorials, reviews and commentaries. All aspects of health maintenance preventative measures and disease treatment interventions are addressed within the journal. Practitioners from all disciplines are invited to submit

\section{Dovepress}

their work as well as healthcare researchers and patient support groups. The manuscript management system is completely online and includes a very quick and fair peer-review system. Visit http://www.dovepress.com/ testimonials.php to read real quotes from published authors. 